and increases the risk of accidents. This study aimed to quantify the problem of cold hands in Arctic open pit mines.

Methods The questionnaire study was carried out in four open pit mines in Russia, Finland, Sweden and Norway. Moreover, skin temperatures as well as thermal sensations were recorded in Kevitsa (Finland) and Aitik (Sweden) open pit mines among 14 male and 2 female mine workers with duties consisting mainly of outdoor work.

Results The questionnaire study $(\mathrm{n}=1323)$ revealed that experienced cold problems were negligible at ambient temperatures above $-10^{\circ} \mathrm{C}$. However, at $-10--20^{\circ} \mathrm{C}, 25 \%$ of workers estimated that their prevailing thermal sensation was "cold". Skin temperature measurements showed that finger skin temperatures were below $15^{\circ} \mathrm{C}$ (a threshold for sharp performance decrement) for $21 \%$ of the working time.

Conclusions The questionnaire study and skin temperature measurements suggest unequivocally that hands/fingers are so cold that manual performance is markedly decreased in more than $20 \%$ of workers/working time. Such a decrease in manual performance increases the risk of accidents. It should be noted that during the skin temperature measurements ambient temperature was never below $-16^{\circ} \mathrm{C}$. Improved cold protection should be directed to cold sensitive workers and tasks especially at ambient temperatures below $-10^{\circ} \mathrm{C}$.

This study was funded by Kolarctic ENPI CBC.

\section{THERMAL AND VISUAL PROBLEMS WHILE USING FAN- ASSISTED RESPIRATOR IN THE COLD}

${ }^{1}$ Sirkka Rissanen, ${ }^{2}$ Merethe Larsen, ${ }^{2}$ Eva Kramvik, ${ }^{2}$ Morten Skandfer, 'Satu Mänttäri, ${ }^{1}$ Hannu Rintamäki. ${ }^{1}$ Finnish Institute of Occupational Health, Oulu, Finland; ${ }^{2}$ University Hospital of Northern Norway, Tromsø, Norway

\subsection{6/injuryprev-2016-042156.393}

Background Respirators protecting against airborne particles and gases are also needed in cold environments. However, low temperature causes special problems such as freezing of exhaled moisture in the respirator, increases respiratory resistance and hampers communication. Fan-assisted respirators aim to solve the problem of respiratory resistance. However, there are a lot of complaints that the high and continuous air flow inside the face shield cools the face and eyes. This study aims to quantify the cooling problem and seeks solutions.

Methods Fan-assisted respirator with the face shield together with the battery-powered fan and filters was used. Air flow rates were 170 and $240 \mathrm{l} / \mathrm{min}$. Exposure temperatures were $-10,-20$ and $-30^{\circ} \mathrm{C}$. Under the face shield the face skin was either unprotected or protected by a facemask (balaclava with a ventilator). Five male volunteers participated in the study. Face skin temperatures were measured at forehead, cheek, nose and lower lip. In the exposure temperature the subjects were standing, stepping and lifting for altogether $30 \mathrm{~min}$.

Results Face skin temperatures were between 5 and $17{ }^{\circ} \mathrm{C}$ and thermal sensation was "cold" without the facemask. While the facemask was used skin temperatures were between 17 and $30^{\circ} \mathrm{C}$ and thermal sensation was "slightly cool". Fogging of the visor started from the sides in 10 to $15 \mathrm{~min}$ (exercise started) and humidity started to freeze soon after, regardless of the use of the facemask.

Conclusions The flow of air inside the fan-assisted respirator decreased skin temperatures to uncomfortable level within $5-10$ min without the facemask. The lowest temperature was measured in the lower lip. The use of facemask kept the skin temperatures in comfort/acceptable level. Freezing of exhaled moisture in the face shield was a marked problem without and with the facemask. It seriously restricted the eyesight causing a critical safety issue. Further development is needed for the respiratory protection in the cold.

\section{SMART PROTECTIVE SOLUTIONS FOR WORK IN THE COLD}

Kirsi Jussila, Sirkka Rissanen, Hannu Rintamäki. Finnish Institute of Occupational Health, Oulu, Finland

\subsection{6/injuryprev-2016-042156.394}

Background Human and industrial activities are increasing in the Arctic. Several countries are involved in Arctic business e.g. through oil and gas, mining, fisheries, tourism, as well as technology suppliers and developers for those fields. Year-round activity in the area involves challenging climate for the industries as well as workers' performance and occupational safety. In the cold, thermal comfort, work capacity and productivity decrease and the risk of mistakes, errors and accidents increase. Peripheral or uncovered body parts, like hands, are the first to cool when humans are exposed to cold resulting in reduced manual and psychomotor performance.

Recently started SmartPro-project (Smart protective solutions for industrial safety and productivity in the cold) aims to assure productivity and occupational safety in cold by developing proactive auxiliary heating solutions for protective clothing and gloves. Methods The project is organised in three work packages (WP). WP1 develops an algorithm for monitoring cold stress for workers, WP2 creates novel gloves which have new design and optimal thermal insulation supported by auxiliary smart heating system, and WP3 is for project management and dissemination.

Results This project will develop novel solutions for interactive heating systems for the hands and early warning systems of critical levels of cold. Smart solutions, such as wireless sensors, wearable computing and auxiliary heating together with material solutions, will be integrated into a protective workwear jacket and novel designed gloves.

Conclusions The SmartPro-project will lead to smarter and safer work in several industries, where workers are frequently exposed to harsh weather environment. Integrating wireless sensors in protective clothing and gloves will provide, together with the knowledge from the thermal environment, an early warning mechanism of critical level of cold exposure on work site and on an individual level in real time.

\section{WINTER TYRE TYPE AND TRAFFIC SAFETY}

${ }^{1}$ Mikko Malmivuo, ${ }^{2}$ Juha Luoma, ${ }^{2}$ Heikki Kanner. ${ }^{1}$ Innomikko Ltd, Finland; ${ }^{2}$ VTT, Finland

\subsection{6/injuryprev-2016-042156.395}

Background The winter tyre type have various effects on traffic safety. These effects have been analysed in three separate studies published between December 2014 - December 2015.

Methods The main questions of the 3 studies were a): what's the safety difference between studded tires and studless tires and b) how can we promote traffic safety connected to winter tires? The 